\title{
Insulin mediators in man: effects of glucose ingestion and insulin resistance
}

\author{
P.N . Shashkin ${ }^{1}$, E . F. Shashkina ${ }^{1}$, E . Fernqvist-Forbes ${ }^{1}$, Y.-P. Z hou ${ }^{2}$, V. G rill $^{2}$, A . K atz ${ }^{1}$ \\ ${ }^{1}$ Department of Surgical Sciences, Division of Clinical Physiology, Karolinska Institute, Karolinska Hospital, Stockholm, Sweden \\ ${ }^{2}$ Department of Molecular Medicine, Endocrine and Diabetes Unit, Karolinska Institute, Karolinska Hospital, Stockholm, \\ Sweden
}

Summary Insulin mediators (inositol phosphoglycans) have been shown to mimic insulin action in vitro and in intact mammals, but it is not known which mediator is involved in insulin action under physiological conditions, nor is it known whether insulin resistance alters the mediator profile under such conditions. We therefore investigated the effects of glucose ingestion on changes in the bioactivity of serum inositol phosphoglycan-like substances (IPG) in healthy men and insulin resistant (obese, non-insulin-dependent diabetic) men. Two classes of mediators were partially purified from serum before and after glucose ingestion. The first was eluted from an anion exchange resin with $\mathrm{HCl} \mathrm{pH} \mathrm{2.0,} \mathrm{and} \mathrm{bioactivity} \mathrm{was} \mathrm{de-}$ termined by activation of pyruvate dehydrogenase in vitro. The second was eluted with $\mathrm{HCl} \mathrm{pH} 1.3$, and bioactivity was determined by inhibition of cyclic AMP-dependent protein kinase. In healthy men, the bioactivity of the $\mathrm{pH} 1.3$ IPG was not altered by glucose ingestion, whereas bioactivity of the $\mathrm{pH} 2.0$ IPG increased to approximately $120 \%$ of the pre-glucose ingestion value at $60-240 \mathrm{~min}$ post-glucose ingestion $(p<0.05$ vs pre-glucose). There was no change in either IPG after glucose ingestion in the insulin-resistant group. These data suggest that the $\mathrm{pH}$ 2.0 IPG plays an important role in mediating insulin's effect on peripheral glucose utilization in man under physiological conditions. The data further show, for the first time, a defective change in the bioactivity of an insulin mediator isolated from insulin-resistant humans after hyperinsulinaemia, suggesting that inadequate generation/release of IPGs is associated with insulin resistance. [Diabetologia (1997) 40: 557-563]

Keywords Inositol phosphoglycans, non-insulin dependent diabetes mellitus, pyruvate dehydrogenase, cyclic AMP dependent protein kinase.
Insulin generates/releases chemical substances that alter the activities of purified enzymes $[1,2]$ and the metabolism of intact cells $[3,4]$ in an insulin mimetic fashion. These substances have therefore been termed mediators or second messengers of insulin

Received: 4 October 1996 and in revised form: 2 January 1997

Corresponding author: Dr. A. Katz, Department of Surgical Sciences, Division of Clinical Physiology, Karolinska Hospital, S-171 76 Stockholm, Sweden

A bbreviations: IPGs, Inositol phosphoglycans; PDH, pyruvate dehydrogenase; PKA, cyclic AMP dependent protein kinase; NIDDM, non-insulin-dependent diabetes mellitus; HM, healthy men; IRM, insulin-resistant men; IGF-1, insulin-like growth factor-1.
[5]. Two different insulin mediators have been separated from rat liver [6]. These mediators have been identified as inositol phosphoglycans (IPGs), containing inositol, non-acetylated amino sugars, neutral sugars, ethanolamine, phosphate and, possibly, amino acids [5]. One contains D-chiro-inositol and activates pyruvate dehydrogenase (PDH) phosphatase, whereas another contains myo-inositol and inhibits cyclic AMP-dependent protein kinase (PKA). Injection of each of these IPGs into low-dose streptozotocin-diabetic rats lowers blood glucose [7].

Body fluids of patients with non-insulin-dependent diabetes mellitus (NIDDM) have abnormally low levels of D-chiro-inositol and the D-chiro-inositol containing IPG (as measured by its D-Chiro-inositol content and bioactivity) $[8,9]$, and it was therefore 
Table 1. Subject characteristics

\begin{tabular}{lllcll}
\hline & $\begin{array}{l}\text { Age } \\
(\text { years })\end{array}$ & $\begin{array}{l}\text { Height } \\
(\mathrm{cm})\end{array}$ & $\begin{array}{l}\text { Weight } \\
(\mathrm{kg})\end{array}$ & $\begin{array}{l}\text { BMI } \\
\left(\mathrm{kg} / \mathrm{m}^{2}\right)\end{array}$ & $\begin{array}{l}\text { Glycated Hb } \\
(\% \text { of total Hb })\end{array}$ \\
\hline Healthy men & $52.3 \pm 2.6$ & $185.0 \pm 2.1$ & $80.8 \pm 0.9$ & $23.9 \pm 0.8$ & $3.3 \pm 0.1$ \\
Insulin resistant men & $59.6 \pm 1.8$ & $185.3 \pm 2.9$ & $100.3 \pm 5.7^{\mathrm{a}}$ & $29.1 \pm 1.3^{\mathrm{b}}$ & $6.8 \pm 0.7^{\mathrm{c}}$ \\
\hline
\end{tabular}

Values are means \pm SEM for $n=6$ healthy men or 7 for insulin resistant men

${ }^{a} p<0.05,{ }^{b} p<0.01,{ }^{c} p<0.001$ vs healthy men by unpaired t-test

suggested that the lack of precursor for the D-chiroinositol containing IPG is related to insulin resistance [9]. Infusion of insulin, resulting in supraphysiologic concentrations of plasma insulin, was shown transiently to increase the content of both myo and Dchiro-inositol in the two respective IPG mediator fractions extracted from muscle biopsies of healthy subjects. These fractions also had increased bioactivities vs the basal state [8]. In patients with NIDDM, supraphysiologic plasma insulin concentrations also resulted in a transient increase in the content of myo-inositol of one mediator fraction extracted from muscle biopsies, but the amount of D-chiro-inositol from the other fraction was below the limit of detection both before and after insulin infusion. Bioactivity measurements were not performed on IPG fractions isolated from the diabetic patients [8]. Thus it is not known which, if any, of these IPGs is involved in insulin action under physiologic conditions, nor is it known whether there is a defect in the generation/release of IPGs (measured by altered bioactivity) in insulin resistant states in response to physiologic increases in plasma insulin. The purpose of the present study was to determine the effects of glucose ingestion on the bioactivity of IPG-like substances isolated from serum of healthy and insulin resistant subjects.

\section{Subjects, materials and methods}

Subjects and patients. Six healthy men (HM) and 7 insulin resistant, obese, diabetic (NIDDM) men (IRM) were studied. Because one aim of this investigation was to study the role of insulin resistance in IPG metabolism, we used obese, NIDDM patients since they are markedly insulin resistant and represent a significant proportion of insulin resistant humans (this issue is further addressed in the Discussion). Physical characteristics are presented in Table 1. Mean duration of diabetes was 6 years (range 2-10). One diabetic patient was treated with diet alone. The other 6 were treated with glibenclamide; of these, 2 were also treated with metformin, 1 with insulin (s.c., NPH), and 1 with a tricyclic antidepressant (amitryptyline). Subjects were instructed to abstain from all medication during the 48-h prior to study. The study protocol was reviewed and approved by the ethics committee of Karolinska Hospital, and informed written consent was given by all participants.

Protocol. Subjects reported to the laboratory in the morning after an overnight fast, and assumed a semi-reclined position. A small plastic catheter was inserted into an antecubital vein for blood sampling. Subjects ingested $75 \mathrm{~g}$ of glucose in
$375 \mathrm{ml}$ of water. Blood samples were drawn before and up to $4 \mathrm{~h}$ after glucose ingestion.

A nalytical. Isotopes $\left(\left[{ }^{32} \mathrm{P}\right]-\mathrm{ATP},\left[1-{ }^{14} \mathrm{C}\right]\right.$-pyruvate $)$ were purchased from Amersham International (Amersham, Bucks, UK). Anion exchange resin (AG 1-X8, formate form) was purchased from Bio-Rad (Stockholm, Sweden). Purified PKA (P4890) and histone IIA (H9250) were purchased from Sigma Chemical Co. (St. Louis, MO., USA). All other chemicals were purchased from either Sigma or Boehringer Mannheim Scandinavia (Bromma, Sweden).

IPG-like substances (IPGs) were isolated from serum essentially as previously described $[8,9]$. Briefly, $1 \mathrm{ml}$ serum (or distilled water for blank) was mixed with $3 \mathrm{ml}$ of extraction solution containing formic acid, 2-mercaptoethanol and EDTA (final concentrations 50,1 and $1 \mathrm{mmol} / \mathrm{l}$, respectively). The samples were heated at $100^{\circ} \mathrm{C}$ for $5 \mathrm{~min}$ and cooled on ice. Thereafter $20 \mathrm{mg}$ of charcoal was added, and $10 \mathrm{~min}$ later the samples were centrifuged $(40000 \times \mathrm{g}, 30 \mathrm{~min})$. The supernatants were neutralized with $\mathrm{NH}_{4} \mathrm{OH}$ to $\mathrm{pH} 6.0$, and centrifugation repeated. Anion exchange resin $(1.6 \mathrm{ml})$ was added to each supernatant. The slurry of resin and supernatant was kept on ice for approximately $20 \mathrm{~h}$ with occasional agitation, then poured into a column and eluted stepwise with 3 bed volumes of distilled water, 5 bed volumes of $\mathrm{HCl} \mathrm{pH} 2.0$ $(10 \mathrm{mmol} / \mathrm{l})$ and 5 bed volumes of $\mathrm{HCl} \mathrm{pH} 1.3(50 \mathrm{mmol} / \mathrm{l})$. The $\mathrm{pH} 1.3$ eluate was neutralized with $\mathrm{NH}_{4} \mathrm{OH}$ to $\mathrm{pH}$ 4.0. The $\mathrm{pH} 1.3$ and 2.0 eluates were frozen, lyophilized twice and finally reconstituted with $200 \mu$ of distilled water. The $\mathrm{pH} 2.0$ fraction activates $\mathrm{PDH}$ [9] and will hereupon be referred to as the $\mathrm{pH}$ 2.0 IPG. The $\mathrm{pH} 1.3$ fraction inhibits PKA [9] and will hereupon be referred to as the pH 1.3 IPG. Satisfactory separation of the two IPGs was demonstrated by showing that the $\mathrm{pH}$ 1.3 IPG did not activate PDH, and that the $\mathrm{pH}$ 2.0 IPG did not inhibit PKA (data not shown). PKA inhibition by the $\mathrm{pH} 1.3$ IPG and PDH activation by the $\mathrm{pH} 2.0$ IPG were concentration dependent (Fig. 1).

The PDH activating fraction has been shown also to contain an inhibitor of PDH $[10,11]$. The two separate activities are resolvable by ethanol treatment, the activator being ethanol insoluble and the inhibitor being ethanol soluble [10]. Therefore, $100 \mu \mathrm{l}$ aliquots of the $\mathrm{pH} 2.0$ IPG were lyophilized, and extracted twice with $1 \mathrm{ml}$ absolute ethanol. The ethanol soluble and insoluble fractions were dried under a stream of $\mathrm{N}_{2}$ and reconstituted in $100 \mu \mathrm{l}$ distilled water. The ethanol insoluble fraction resulted in significantly higher PDH activity than the water fraction (Fig.1, middle). The ethanol soluble fraction contained a compound that inhibited $\mathrm{PDH}$, and this inhibition was concentration dependent (Fig. 3, bottom). Consequently, the ethanol soluble and insoluble fractions were used to measure bioactivity of the $\mathrm{pH} 2.0$ eluate.

Soluble PDH complex, which contains PDH, as well as PDH kinase and phosphatase, was isolated from pig heart as described elsewhere [12], and was kindly provided by Dr. D. Priestman. For analysis of the bioactivity of the PDH activator, methods previously described were used $[9,13]$ with some modifications. Ten $10 \mu \mathrm{l}$ of PDH complex (diluted in $2 \%$ rat serum, 


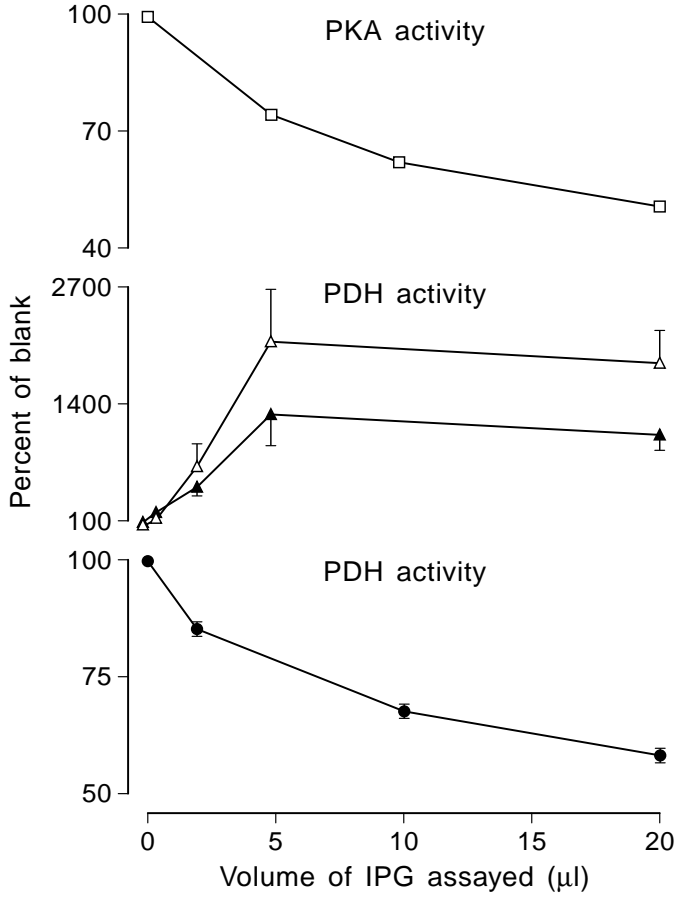

Fig. 1. Concentration dependency of inositol phosphoglycans (IPG) bioactivity in vitro. Values are from a representative experiment performed in duplicate (top) or means \pm SEM for $n=5$ (middle) and $n=3$ (bottom). Top, protein kinase (PKA) inhibition by $\mathrm{pH} 1.3$ IPG; middle, $\mathrm{PDH}$ activation by $\mathrm{pH} 2.0$ IPG from ethanol untreated fractions $(\boldsymbol{\Delta})$ and ethanol insoluble fractions (2 09); bottom, pyruvate dehydrogenase (PDH) inhibition by $\mathrm{pH} 2.0$ ethanol soluble fractions. IPG volumes are stock volumes per $100 \mu$ l total volume assayed. In middle panel open symbols are significantly higher than solid symbols at sample volumes of $2-20 \mu \mathrm{l}(\mathrm{p}<0.01$ by paired t-test)

$2.5 \mathrm{mmol} / \mathrm{l}$ EDTA, $5 \mathrm{mmol} / \mathrm{l}$ dithiothreitol (DTT), $0.1 \mathrm{mmol} / \mathrm{l}$ $\mathrm{N} \alpha$-p-tosyl-L-lysine chloromethyl ketone (TLCK), $2 \%$ trypsin inhibitor, $2 \%$ trasylol, $0.2 \mathrm{mmol} / \mathrm{K} \mathrm{KCl}, 0.5 \%$ triton $\mathrm{X}-100$ and $50 \mathrm{mmol} / 1$ 4-(2-hydroxyethyl)-1-piperazineethane sulphonic acid, $\mathrm{pH} 7.5$ ) were incubated with $20 \mu \mathrm{l}$ of diluted mediator (equivalent to $0.5 \mu \mathrm{l}$ of stock), or blank, and $50 \mu \mathrm{l}$ of a buffer consisting of $40 \mathrm{mmol} / \mathrm{l}$ potassium phosphate, $2 \mathrm{mmol} / \mathrm{l} \mathrm{DTT}$, $0.2 \mathrm{mmol} / 1 \mathrm{CoA}, 0.2 \mathrm{mmol} / 1$ thiamine pyrophosphate (TPP), $1 \mathrm{mmol} / \mathrm{N} \mathrm{NAD}^{+}$, and $2 \mathrm{mg} / \mathrm{ml}$ bovine serum albumin, $\mathrm{pH} 7.4$ in an uncapped $1.5 \mathrm{ml}$ eppendorf tube for $10 \mathrm{~min}$ at $37^{\circ} \mathrm{C}$. Thereafter, $20 \mu \mathrm{l}$ of a mixture of pyruvate $(5 \mathrm{mmol} / \mathrm{l}$, specific activity $0.6 \mathrm{mCi} / \mathrm{mmol}$ ) and $\mathrm{KF}(500 \mathrm{mmol} / \mathrm{l}$ ) was added (final volume $100 \mu \mathrm{l}$ ), and the vial was immediately transferred to a $20 \mathrm{ml}$ glass scintillation vial containing $1 \mathrm{ml}$ of $1.2 \mathrm{~N} \mathrm{KOH}$. The vial was immediately closed with a perforated cap and a rubber bladder. After $20 \mathrm{~min}$ at $37^{\circ} \mathrm{C}$, the PDH reaction was stopped by injecting $100 \mu \mathrm{l}$ of $15 \%$ trichloracetic acid through the rubber bladder into the incubation mixture. After an additional $2 \mathrm{~h}$ at $37^{\circ} \mathrm{C}$, the vials were opened, the eppendorf tubes were discarded, and $10 \mathrm{ml}$ of scintillation cocktail (Ultima Gold; Packard, Meriden, CT, USA) was added and mixed with the $\mathrm{KOH}$ containing the trapped ${ }^{14} \mathrm{CO}_{2}$, and subsequently counted. To study the bioactivity of the PDH inhibitor, the same procedure as above was used, except that the mediator volume was equivalent to $2 \mu \mathrm{l}$ of stock and $\mathrm{CaCl}_{2}$ (final concentration in $100 \mu \mathrm{l}=$ $50 \mu \mathrm{mol} / \mathrm{l}$ ) and $\mathrm{MgCl}_{2}$ (final concentration in $100 \mu \mathrm{l}=10 \mu \mathrm{mol} /$ 1) were added during the preincubation step. This increased PDH activity and facilitated detection of the inhibitor [10].
Bioactivity of the $\mathrm{pH}$ 1.3 IPG was determined by following PKA-dependent incorporation of ${ }^{32} \mathrm{P}$ from radioactive ATP into histone essentially as described earlier [1], with slight modifications. Mediator $(20 \mu \mathrm{l})$ (equivalent to $10 \mu \mathrm{l}$ of stock) or blank was preincubated with $60 \mu \mathrm{l}$ of a buffer consisting of $20 \mathrm{mmol} / 1 \mathrm{MgCl}_{2}, 2 \mu \mathrm{mol} / \mathrm{l}$ cyclic AMP, $0.6 \mathrm{mmol} / \mathrm{l}$ ATP (specific activity $\cong 3 \mathrm{mCi} / \mu \mathrm{mol}), 1 \mathrm{mg} / \mathrm{ml}$ histone, $200 \mathrm{mmol} / 12$ [N-morpholino] ethanesulfonic acid (MES), pH 7.0. (PKA activity in the absence of cyclic AMP amounted to $20-40 \%$ of the activity in the presence of cylic AMP.) The reaction was started by addition of $20 \mu \mathrm{l} \mathrm{PKA}$. Incubation was at $35^{\circ} \mathrm{C}$ for $10 \mathrm{~min}$, and the reaction was stopped by spotting $75 \mu \mathrm{l}$ of the incubation mixture on $3 \mathrm{MM}$ paper squares (Whatman, Maidstone, England). The papers were then washed in $10 \%$ TCA $(10 \mathrm{~min}), 5 \%$ TCA $(2 \times 5 \mathrm{~min})$ and $95 \%$ ethanol $(5 \mathrm{~min})$, dried and counted. All mediator assays were performed in duplicate.

To obtain further information on the components of the isolated bioactive fractions, nitrous acid exposure experiments were performed. Exposure of IPGs to nitrous acid results in deamination of non- $\mathrm{N}$-acetylated hexosamines, with subsequent cleavage of adjacent glycosidic bonds (releasing inositol) and loss of bioactivity $[3,4,6]$. Freeze-dried samples were reconstituted with $50 \mathrm{mmol} / \mathrm{l}$ sodium acetate, $\mathrm{pH} 3.5 \pm$ sodium nitrite $\left(\mathrm{NaNO}_{2}\right)$ and incubated at $37^{\circ} \mathrm{C}$ for $5 \mathrm{~h}$. The samples were neutralized to $\mathrm{pH} 6$, freeze-dried, reconstituted with water and assayed. $\mathrm{NaNO}_{2}$ inhibited bioactivity of the PDH activating fraction by approximately $50 \%$ and the PKA inhibiting fraction by approximately $65 \%$, while not affecting the activity of the blanks (data not shown). Taken together, the presence of bioactivity after the isolation procedures used, and the significant loss of bioactivity after nitrous acid treatment, suggest that the bioactive fractions contained IPGs.

Plasma glucose was measured with the glucose oxidase technique using a glucose analyser (Beckman Instruments, Fullerton, Calif., USA). Free insulin [14] and C-peptide (Kit RB-315; Milab, Malmö, Sweden) were determined by radioimmunoassay. Glycated haemoglobin was determined by ion exchange chromatography [15].

Statistical analysis. Results within groups were analysed with either the paired t-test or a one-way repeated measures analysis of variance (ANOVA) where appropriate. When the ANOVA resulted in a significant $F$-ratio $(p<0.05)$, the location of significance was determined with the Newman-Keuls test. Differences between groups were determined with the unpaired ttest. Values are presented as means \pm SEM, unless otherwise indicated.

\section{Results}

Glucose ingestion resulted in a small rise in plasma glucose in HM and a larger rise in IRM (Table 2). Peak insulin values were observed at $30 \mathrm{~min}$ after glucose ingestion in HM followed by a continuous decline, while the peak in IRM occurred later and remained elevated up to 240 min after glucose ingestion. The large variability in plasma insulin at $30 \mathrm{~min}$ postglucose ingestion in $\mathrm{HM}$ was due to a large increase in insulin in one subject ( $744 \mathrm{pmol} / \mathrm{l})$. The similar Cpeptide values at $120 \mathrm{~min}$ after glucose ingestion in both groups suggest that the integrated insulin secretion in both groups was similar after glucose ingestion. Plasma insulin was significantly higher in IRM than in 
Table 2. Effects of glucose ingestion on plasma glucose and hormone concentrations

\begin{tabular}{|c|c|c|c|c|c|}
\hline & \multicolumn{5}{|c|}{ Time after glucose ingestion (min) } \\
\hline & 0 & 30 & 60 & 120 & 240 \\
\hline \multicolumn{6}{|l|}{ Glucose (mmol/l) } \\
\hline Healthy men & $5.3 \pm 0.1$ & $8.6 \pm 0.4^{\mathrm{c}}$ & $7.3 \pm 0.5^{b}$ & $5.8 \pm 0.7$ & $4.3 \pm 0.3$ \\
\hline Insulin resistant men & $12.4 \pm 1.1$ & $17.3 \pm 1.3^{\mathrm{c}}$ & $20.1 \pm 1.0^{\mathrm{c}}$ & $21.9 \pm 1.2^{\mathrm{c}}$ & $14.8 \pm 1.5^{\mathrm{a}}$ \\
\hline \multicolumn{6}{|l|}{ Insulin (pmol/l) } \\
\hline Healthy men & $31 \pm 3$ & $273 \pm 98^{b}$ & $200 \pm 32^{\mathrm{a}}$ & $146 \pm 35$ & $28 \pm 5$ \\
\hline Insulin resistant men & $77 \pm 12$ & $145 \pm 27$ & $188 \pm 55^{\mathrm{b}}$ & $196 \pm 50^{\mathrm{b}}$ & $124 \pm 32$ \\
\hline \multicolumn{6}{|l|}{ C-peptide (nmol/l) } \\
\hline Healthy men & $0.76 \pm 0.12$ & - & - & $1.59 \pm 0.14^{\mathrm{b}}$ & - \\
\hline Insulin resistant men & $1.00 \pm 0.12$ & - & - & $1.95 \pm 0.31^{\mathrm{a}}$ & - \\
\hline
\end{tabular}

Values are means \pm SEM for $\mathrm{n}=6$ (healthy men) or 7 (insulin resistant men)

${ }^{\mathrm{a}} \mathrm{p}<0.05,{ }^{\mathrm{b}} \mathrm{p}<0.01,{ }^{\mathrm{c}} \mathrm{p}<0.001$ vs 0 min in corresponding group by ANOVA followed by Newman-Keuls test

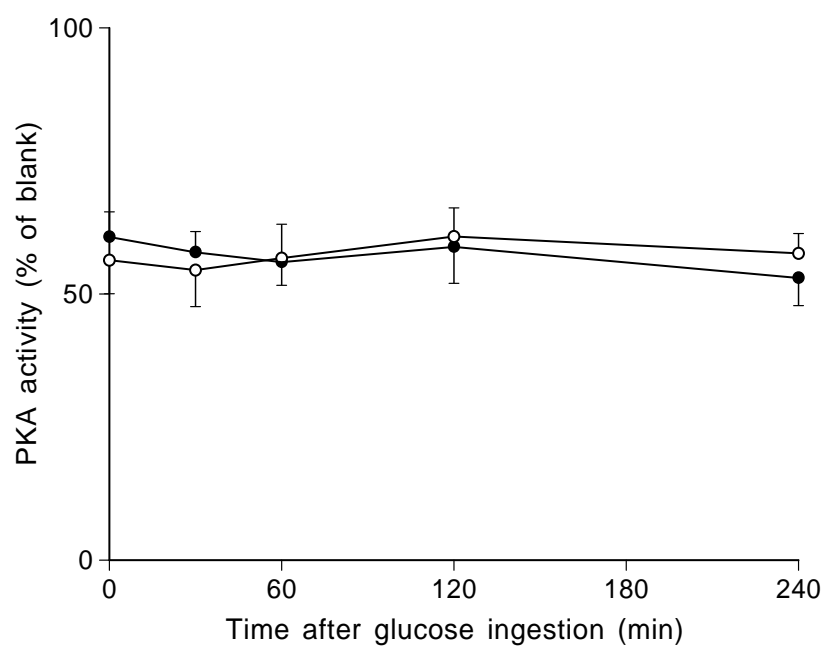

Fig. 2. Effects of glucose ingestion on bioactivity of $\mathrm{pH} 1.3$ inositol phosphoglycans (IPG). Values are means \pm SEM and are expressed as a percentage of the blank. $\bigcirc$, healthy men (HM); , insulin-resistant men (IRM). There was no significant change in bioactivity in either group after glucose ingestion ( $p>0.05$ by ANOVA). Protein kinase activity (PKA) at $0 \mathrm{~min}$ was $0.40 \pm 0.04 \mathrm{nmol} \cdot \mathrm{mg}$ protein ${ }^{-1} \cdot \mathrm{min}^{-1}$ for $\mathrm{HM}$ and $0.43 \pm 0.04$ for IRM $(p>0.05$ by unpaired t-test $)$; blank $=0.72$ $\mathrm{nmol} \cdot \mathrm{mg}$ protein ${ }^{-1} \cdot \mathrm{min}^{-1}$

HM at $0(p<0.01)$ and $240 \min (p<0.05$ by unpaired $t-$ test), but not significantly different at the other times. The changes in plasma glucose and insulin values after glucose ingestion in the obese diabetic patients suggest that these patients were severely insulin resistant.

There were no changes in the bioactivity of the $\mathrm{pH}$ 1.3 IPG in either group after glucose ingestion, nor were there any differences in bioactivity between groups in the basal state (Fig. 2). In some cases, the inhibition of PKA by the pH 1.3 IPG (from both HM and IRM groups) was measured also in the absence of cyclic AMP. The pH 1.3 IPG also inhibited PKA in the absence of cyclic AMP but, again, there was no change in bioactivity after glucose ingestion (data not shown). Bioactivity was also measured after additional dilution of the $\mathrm{pH}$ 1.3 IPG in the presence of cyclic AMP, but still there was no change after glucose ingestion (data not shown).

Preliminary experiments suggested that an increase in bioactivity of the ethanol insoluble $\mathrm{pH} 2.0$ IPG after glucose ingestion (vs preglucose) could be detected at a sample volume equivalent to $0.5 \mu \mathrm{l}$ of stock, which corresponds to $2.5 \mu \mathrm{l}$ of serum. Therefore, this volume was used in analysis of the ethanolinsoluble IPG. In HM, bioactivity of the $\mathrm{pH} 2.0$ IPG was significantly elevated at 60-240 min post-glucose ingestion ( $\sim 120 \%$ of basal) (Fig. 3.A and B). In contrast, no change in bioactivity was detected in IRM after glucose ingestion. Also there was no significant difference in bioactivity of the pH 2.0 IPG between groups in the basal state (Fig.3). This was contrary to what we expected, considering recent reports that NIDDM patients have lower levels of D-chiro-inositol in urine, and lower amounts of D-chiro-inositol in the pH 2.0 IPG isolated from muscle, haemodialysate and urine, as well as lower bioactivity of the IPG vs control patients $[8,9]$. Therefore, we repeated the analyses of the samples obtained in the basal state (all in the same run) using more concentrated samples (equivalent to $2 \mu \mathrm{l}$ of stock IPG). However, again, no significant difference was noted (blank = $0.6 \mathrm{nmol} \cdot \mathrm{mg}$ protein ${ }^{-1} \cdot \mathrm{min}^{-1} ; \quad \mathrm{HM}=3.1 \pm 0.3$; $\operatorname{IRM}=2.3 \pm 0.6, p>0.15$ ).

No significant changes were detected in PDH inhibiting activity in either group after glucose ingestion (Fig.4). There was no significant difference in PDH inhibiting bioactivity between groups in the basal state (Fig. 4). Galasko et al. [16,17] recently characterized an IPG isolated from plasma of NIDDM patients that inhibited PDH phosphatase to a greater extent than did IPG isolated from control plasma. We therefore repeated the analysis of the samples obtained in the basal state (all in the same run) using more concentrated samples (equivalent to $10 \mu \mathrm{l}$ of stock). Again, there was no significant difference between groups (data not shown). Our PDH complex inhibitor has not been characterized, and has been isolated by procedures different from those employed by Galasko 

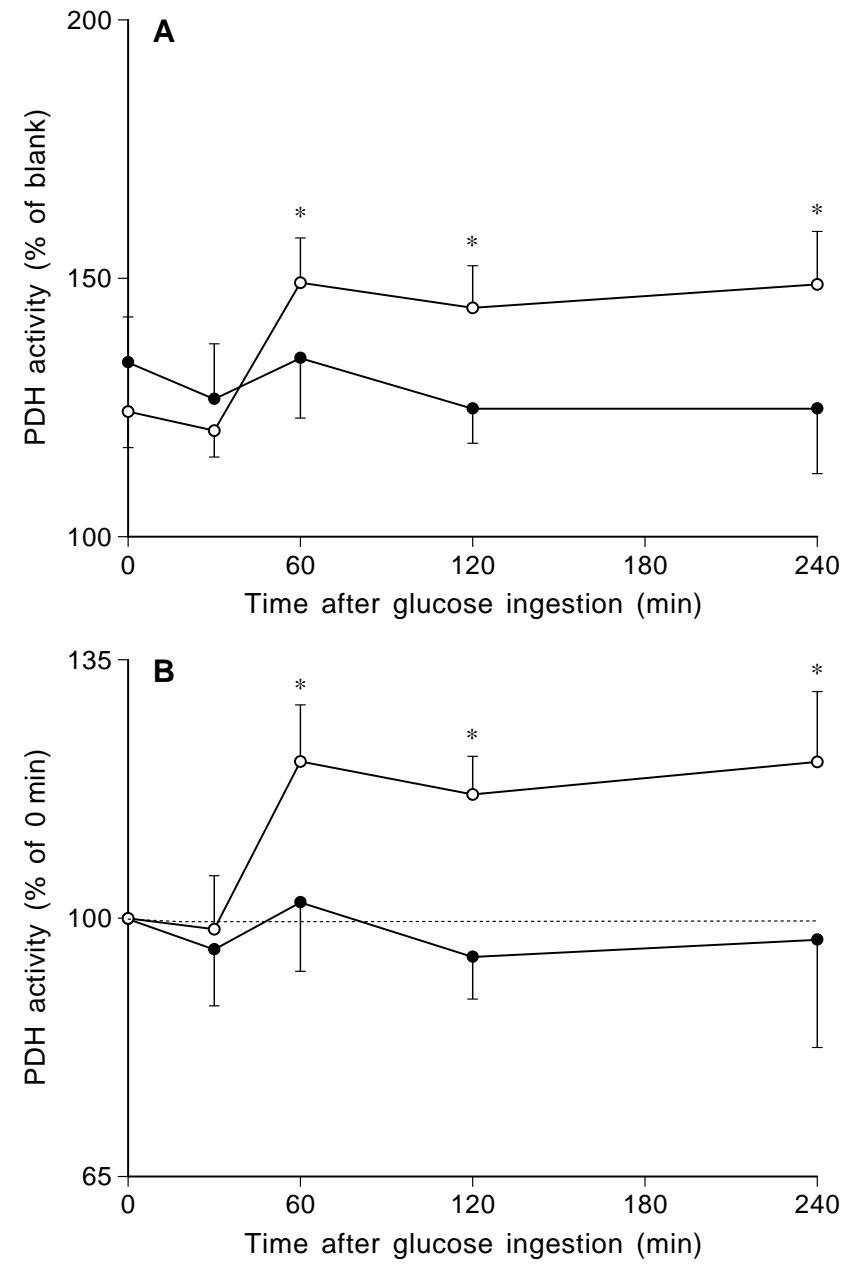

Fig. 3A , B. Effects of glucose ingestion on bioactivity of $\mathrm{pH} 2.0$ ethanol insoluble inositol phosphoglycans (IPG). Values are means \pm SEM and are expressed as a percentage of the blank (A) and a percentage of the value at $0 \min (=100 \%)$ (B). $\bigcirc$, healthy men (HM); $\mathbf{O}$, insulin resistant men (IRM). There was no significant change in bioactivity in IRM after glucose ingestion ( $p>0.05$ by ANOVA). PDH activity at 0 min was $0.67 \pm 0.07 \mathrm{nmol} \cdot \mathrm{mg}$ protein ${ }^{-1} \cdot \mathrm{min}^{-1}$ for $\mathrm{HM}$ and $0.73 \pm 0.03$ for IRM ( $p>0.05$ by unpaired t-test $)$; blank $=0.55 \mathrm{nmol} \cdot \mathrm{mg}$ protein $^{-1} \cdot \mathrm{min}^{-1}$. $* \mathrm{p}<0.05$ vs 0 min in corresponding group by ANOVA followed by Newman-Keuls test

et al. $[16,17]$. Therefore, a direct comparison between studies is currently not possible.

\section{Discussion}

A major finding in the present study is that only one of the measured IPGs, the $\mathrm{pH}$ 2.0 PDH activator, increased after glucose ingestion in HM. The increase was detected only after plasma insulin increased, suggesting that the hormone was the primary variable that promoted the generation/release of the $\mathrm{pH} 2.0$ $\mathrm{PDH}$ activator. It is conceivable that other growth factors, which have been shown to release IPGs from isolated cells [4], could have increased in concentration

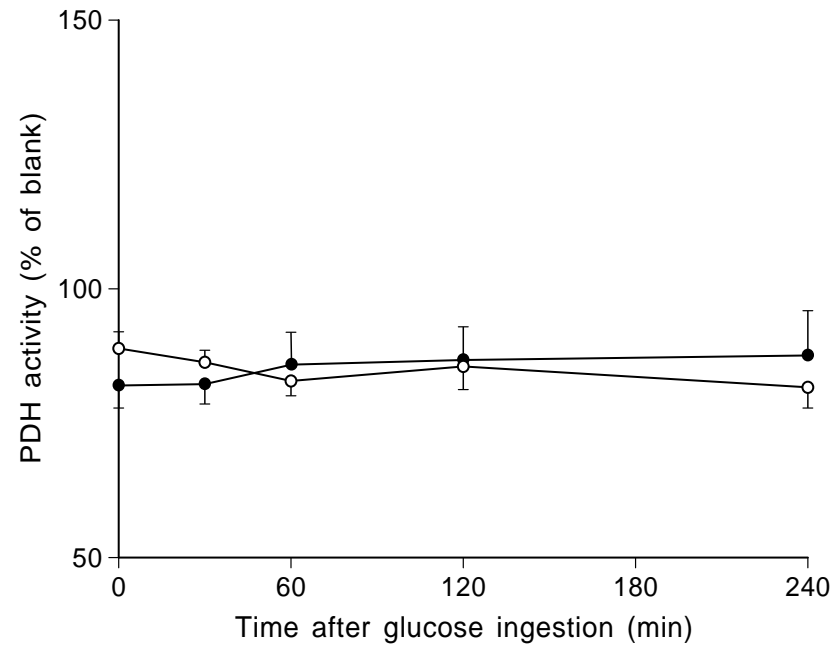

Fig. 4. Effects of glucose ingestion on bioactivity of $\mathrm{pH} 2.0$ ethanol soluble fraction. Values are means \pm SEM and are expressed as a percentage of the blank. $\bigcirc$, healthy men (HM); , insulin resistant men (IRM). There was no significant change in bioactivity in either group after glucose ingestion ( $p>0.05$ by ANOVA). Pyruvate dehydrogenase (PDH) activity at $0 \mathrm{~min}$ was $3.3 \pm 0.1 \mathrm{nmol} \cdot \mathrm{mg}$ protein ${ }^{-1} \cdot \mathrm{min}^{-1}$ for IRM and $3.6 \pm 0.1$ for $\mathrm{HM}$; blank $=4.0 \mathrm{nmol} \cdot \mathrm{mg}$ protein ${ }^{-1} \cdot \mathrm{min}^{-1}$

after glucose ingestion, and thereby be responsible for the increase in the $\mathrm{pH} 2.0 \mathrm{PDH}$ activator. However, we are not aware of any studies that have demonstrated an increase in free insulin-like growth factor-I (IGF-I), epidermal growth factor or nerve growth factor (all of which apparently release IPGs from isolated cells [4]) after glucose ingestion. On the other hand, glucose ingestion results in decreases in serum concentrations of IGF binding protein-1, which binds IGF-I $[18,19]$. A decrease in IGF binding protein-1 should result in an increase in the free concentration of IGF-I. However, the decrease in serum IGF binding protein-1 begins at 90-120 min after glucose ingestion $[18,19]$, whereas the peak increase in the $\mathrm{pH}$ 2.0 PDH activator occurs between 30-60 min after glucose ingestion (Fig. 3). It is thus unlikely that the initial increase in the $\mathrm{pH} 2.0 \mathrm{PDH}$ activator is due to increases in serum levels of free IGF-1.

Consistent with our suggestion that the increase in plasma insulin is the factor primarily responsible for the changes in the $\mathrm{pH}$ 2.0 $\mathrm{PDH}$ activator in the present study is the finding that the bioactivity of the $\mathrm{pH}$ 2.0 IPG isolated from skeletal muscle [8] and serum (Shashkin et al., unpublished observations) of healthy humans increased during euglycaemic hyperinsulinaemia. Moreover, half-maximal release of the $\mathrm{PDH}$ activator from isolated rat liver plasma membranes occurs at an insulin concentration of $20 \mu \mathrm{U} /$ $\mathrm{ml}$ [11], which is within the range of the increases observed in plasma insulin in the present study.

The increases in serum PDH activator observed in the present study (expressed as a percent of basal) are virtually identical to those reported previously in a 
group of healthy young subjects after glucose ingestion [20]. In addition, we now show that the bioactivities of the other measured fractions did not change after glucose ingestion. These results, together with the findings that purified IPGs ( $\mathrm{pH} 1.3$ and 2.0) stimulate peripheral glucose utilization in rats [7], suggest that of the IPGs measured, the $\mathrm{pH}$ 2.0 PDH activator is most important in mediating insulin's effect on peripheral glucose utilization under physiological conditions in man.

Another important finding was the lack of change in the $\mathrm{pH}$ 2.0 PDH activator after glucose ingestion in IRM. To our knowledge, this is the first report of a defective change in the bioactivity of an insulin mediator isolated from insulin resistant humans after hyperinsulinaemia. The lack of increase in the $\mathrm{pH} 2.0$ $\mathrm{PDH}$ activator in IRM is consistent with the observation that euglycaemic hyperinsulinaemia failed to increase the D-chiro-inositol content of the $\mathrm{pH} 2.0$ IPG isolated from muscle biopsies of patients with NIDDM [8]. Thus, inadequate availability of precursor (D-Chiro-inositol) in insulin sensitive tissues may explain the lack of increase in the PDH activator after glucose ingestion in the IRM group.

Since the IRM subjects were insulin resistant, diabetic and obese, it is not clear which factor was responsible for the lack of increase in the serum PDH activator after glucose ingestion. In this regard it is noteworthy that adipocytes isolated from the genetically inbred insulin resistant Goto-Kakizaki rat, a model of non-obese NIDDM, which has a low rate of urinary chiro-inositol excretion, did not release IPGs in response to insulin, whereas adipocytes from control rats did release IPGs in response to insulin [21]. Moreover, four different states of insulin resistance, i.e. glucocorticoid treatment, streptozotocininduced diabetes, aging and genetic obesity, are associated with similar defects in the ability of insulin to elicit the release of IPGs from isolated hepatocytes [22]. This suggests that insulin resistance, rather than diabetes or obesity, is the factor primarily responsible for the lack of increase in the serum PDH activator after glucose ingestion in the IRM group.

Larner and co-workers $[8,9]$ have shown that patients with NIDDM have low levels of D-chiro-inositol in urine, and smaller amounts of D-chiro-inositol have been recovered from the $\mathrm{pH}$ 2.0 IPG isolated from various body fluids. Moreover, bioactivity of the $\mathrm{pH}$ 2.0 IPG isolated from haemodialysate, urine and muscle from NIDDM patients was attenuated vs control [9]. On the other hand, Ostlund et al. [23] showed that patients with NIDDM, as well as insulin-dependent diabetes IDDM, excreted substantially more D-chiro-inositol in urine than obese nondiabetic patients (control group), while plasma Dchiro-inositol levels were similar among the three groups. The possibility exists, however, that the obese non-diabetic patients were insulin resistant [24], and therefore were not appropriate control subjects. The present results show no significant differences in bioactivity of the $\mathrm{pH}$ 2.0 $\mathrm{PDH}$ activator between groups in the basal state. The reason(s) for the seemingly different results is unclear. Perhaps differences in the severity of the diabetic state between the diabetic patients in the study of Asplin et al. [9] and those in the present study can explain the different findings on bioactivity. Unfortunately, information on metabolic control (e.g. glycaemia, glycated haemoglobin) in the study of Asplin et al. [9] was not reported.

It should be noted that increases in serum IPGs after hyperinsulinaemia probably do not reflect and are not proportional to changes in the intracellular IPG content (e.g. in muscle). IPGs are considered to be anchored to the outside of the plasma membrane of cells $[3,4]$. After insulin administration, the IPGs are rapidly released into the extracellular space and transported into the cell [25], where they mediate at least some of insulin's actions [4]. The cellular IPG content increases rapidly but only transiently [8]. It is therefore likely that the increased and sustained levels of the $\mathrm{pH}$ 2.0 IPG in HM serum are a consequence of an initial, rapid release from insulin sensitive tissues, coupled with a slow removal from the extracellular space.

An interesting observation was that glucose ingestion did not alter the bioactivity of the $\mathrm{pH} 1.3$ IPG. High concentrations of insulin increase bioactivity of the pH 1.3 IPG as well as the myo-inositol content of the IPG isolated from skeletal muscle $[1,8]$ and liver [26]. The lack of increase in the serum $\mathrm{pH}$ 1.3 IPG in the present study could thus be due to an insufficient increase in the extracellular insulin concentration, suggesting differential sensitivities of different IPG generating/releasing systems to insulin. Earlier it was shown in rat liver particulate fractions that the PDH activator increased in the presence of a low concentration of insulin while the adenylate cyclase inhibitor did not change at the same insulin concentration [10]. These findings support the idea of differential sensitivities of different IPGs to insulin.

In conclusion, glucose ingestion increases the bioactivity of the $\mathrm{pH} 2.0 \mathrm{PDH}$ activator, but not the $\mathrm{pH}$ 1.3 IPG, suggesting that the $\mathrm{pH} 2.0 \mathrm{PDH}$ activator plays an important role in mediating insulin's effect on peripheral glucose utilization under physiological conditions in man. Because no changes in IPGs were observed in IRM, the results suggest that inadequate generation/release of IPGs is associated with insulin resistance in man.

A cknowledgements. The authors are grateful to Dr. L.C. Huang for her helpful suggestions in setting up the procedures for isolating inositol phosphoglycans. This research was supported by grants from Stiftelsen för Gamla Tjänarinnor, Loo and Hans Ostermans Foundation, The Swedish Institute (304/ GB), The Marianne and Marcus Wallenberg Foundation, Gunvor and Josef Aners Foundation, Tore Nilsons Fund and The Karolinska Institute. 


\section{References}

1. Larner J, Galasko G, Cheng K, DePaoli-Roach AA, Huang L, Daggy P, Kellogg J (1979) Generation by insulin of a chemical mediator that controls protein phosphorylation and dephosphorylation. Science 206: 1408-1410

2. Jarett L, Seals JR (1979) Pyruvate dehydrogenase activation in adipocyte mitochondria by an insulin-generated mediator from muscle. Science 206: 1407-1408

3. Saltiel A, Cuatrecasas P (1988) In search of a second messenger for insulin. Am J Physiol 255:C1-C11

4. Romero G, Larner J (1993) Insulin mediators and the mechanism of insulin action. Adv Pharmacol 24: 21-50

5. Huang LC, Larner J (1993) Inositol phosphoglycan mediators of insulin action. The special role of chiroinositol in insulin resistance. Adv Prot Phosphatases 7: 373-392

6. Larner J, Huang LC, Schwartz CFW et al. (1988) Rat liver insulin mediator which stimulates pyruvate dehydrogenase phosphatase contains galactosamine and D-chiroinositol. Biochem Biophys Res Comm 151: 1416-1426

7. Huang LC, Fonteles MC, Houston DB, Zhang C, Larner J (1993) Chiroinositol deficiency and insulin resistance. III. Acute glycogenic and hypoglycemic effects of two inositol phosphoglycan insulin mediators in normal and streptozotocin-diabetic rats in vivo. Endocrinology 132: 652-657

8. Kennington AS, Hill CR, Craig J et al. (1990) Low urinary chiro-inositol excretion in non-insulin-dependent diabetes mellitus. New Engl J Med 323: 373-378

9. Asplin I, Galasko G, Larner J (1993) Chiro-inositol deficiency and insulin resistance: a comparison of the chiroinositol- and the myo-inositol-containing insulin mediators isolated from urine, hemodialysate, and muscle of control and type II diabetic subjects. Proc Natl Acad Sci USA 90: 5924-5928

10. Saltiel A, Siegel M, Jacobs S, Cuatrecasas P (1982) Putative mediators of insulin action: regulation of pyruvate dehydrogenase and adenylate cyclase activities. Proc Natl Acad Sci USA 79: 3513-3517

11. Suzuki S, Toyota T, Tamura S et al. (1987) ATP$\mathrm{Mn} 2+$ stimulates the generation of a putative mediator of insulin action. J Biol Chem 262: 3199-3204

12. Kerbey AL, Radcliffe PM, Randle PJ, Sugden PH (1979) Regulation of kinase reactions in pig heart pyruvate dehydrogenase complex. Biochem J 181: 427-433

13. Newman JD, Armstrong JM, Bornstein J (1985) Assay of insulin mediator activity with soluble pyruvate dehydrogenase phosphatase.Endocrinology 116: 1912-1919

14. Arnqvist H, Olsson P-O, von Shenck H (1987) Free and total insulin determined after precipitation with polyethylene glycol: analytical characteristics and effects of sample handling and storage. Clin Chem 33: 93-96

15. Jeppsson JO, Jerntorp P, Sundkvist G, Englund H, Nylund V (1986) Measurement of hemoglobin $A 1_{c}$ by a new liquid chromatographic assay: methodology, clinical utility, and relation to glucose tolerance evaluated. Clin Chem 32: 1867-1872

16. Galasko GTF, Bao Y, Broomfield SJ, Hooper NM, Turner AJ, Larner J (1995) Circulating factors and insulin resistance. I. A novel myoinositol 1,2-cyclic phosphate phosphoglycan insulin antagonist from human plasma is elevated in noninsulin-dependent diabetes mellitus. J Clin Endocrinol Metab 80: 2419-2429

17. Galasko GTF, Abe S, Lilley K, Huang LC, Zhang C, Larner J (1996) Circulating factors and insulin resistance. II. The action of the novel myo-inositol 1,2-cyclic inositol phosphate phosphoglycan insulin antagonist from human plasma in regulating pyruvate dehydrogenase phosphatase. J Clin Endocrinol Metab 81: 1051-1057

18. Rutanen E-M, Stenman S, Blum W, Kärkkäinen T, Lehtovirta P, Stenman U-H (1993) Relationship between carbohydrate metabolism and serum insulin-like growth factor system in postmenopausal women: comparison of endometrial cancer patients with healthy controls. J Clin Endocrinol Metab 77: 199-204

19. O’Sullivan AJ, Kelly JJ, Hoffman DM, Baxter RC, Ho KKY (1995) Energy metabolism and substrate oxidation in acromegaly. J Clin Endocrinol Metab 80: 486-491

20. Sinha MK, Caro JF (1985) Presence of an activator of pyruvate dehydrogenase in human circulation: elevation following a glucose load and possible relation to an insulin mediator. Biochem Biophys Res Comm 129: 41-45

21. Farese RV, Standaert ML, Yamada K et al. (1994) Insulininduced activation of glycerol-3-phosphate acyltransferase by a chiroinositol-containing insulin mediator is defective in adipocytes of insulin-resistant, type II diabetic, GotoKakizaki rats. Proc Natl Acad Sci USA 91: 11040-11044

22. Sanchez-Gutierrez JC, Sanchez-Arias JA, Valle JC, Guadano A, Samper B, Mato JM, Feliu JE (1994) Insulin resistance in the genetically obese (fa/fa) rats: changes in the glycosyl-phosphatidylinositol signaling system. Endocrinology 134: 1485-1492

23. Ostlund RE, McGill JB, Herskowitz I, Kipnis DM, Santiago JV, Sherman WR (1993) D-chiro-inositol metabolism in diabetes mellitus. Proc Natl Acad Sci USA 90: 9988-9992

24. Larner J, Craig JW (1996) Urinary myo-inositol-to-chiroinositol ratios and insulin resistance. Diabetes Care 19: $76-78$

25. Alvarez JF, Sanchez-Arias JA, Guadano A, Estevez F, Varela I, Feliu JE, Mato JM (1991) Transport in isolated rat hepatocytes of the phospho-oligosaccharide that mimics insulin action. Biochem J 274: 369-374

26. Malchoff CD, Huang L, Gillespie N, Villar-Palasi C, Schwartz CFW, Cheng K, Hewlett EL, Larner J (1987) A putative mediator of insulin action which inhibits adenylate cyclase and adenosine 3,5 -monophosphate-dependent protein kinase: partial purification from rat liver: site and kinetic mechanism of action. Endocrinology 120: 1327-1337 